\title{
Dampak Pemanfaatan Ruang terhadap Ketersediaan Air Kawasan Danau Sentani Sekitar Sub Das Expo
}

\section{Impact of Space Utilization on Sentani Lake Water Availability Around The Expo Watershed}

\author{
Dantje William Kawer ${ }^{1}$, Murshal Manaf ${ }^{2}$ dan Syafri ${ }^{2}$ \\ ${ }^{1}$ Magister Perencanaan Wilayah dan Kota Program Pascasarjana Universitas Bosowa \\ ${ }^{2}$ Program Studi Perencanaan Wilayah dan Kota Program Pascasarjana Universitas Bosowa \\ E-mail: danwkawer@gmail.com
}

Diterima: 20 Februari 2019/Disetujui 07 Juni 2019

\begin{abstract}
Abstrak. Ruang sebagai wadah tempat manusia beraktifitas, seyogyanya harus dikelola dan dimanfaatkan dengan baik. Pemanfaatan ruang yang sesuai dengan daya dukung, akan menciptakan keseimbangan dan kelestarian lingkungan hidup. Pemanfaatan ruang Sub DAS Expo melalui upaya pemanfaatan lahan yang optimal sangat dibutuhkan untuk menjaga keberlanjutan ekosistem yang ada, dan mempertahankan kualitas lingkungan, serta menjaga keseimbangan antara kegiatan masyarakat dengan lingkungan di Sub DAS Expo. Rumusan Masalah "Bagaimana pengaruh pemanfaatan ruang terhadap kondisi aktual ketersediaan air di Sub DAS Expo?" Sedangkan Tujuan penelitian yaitu 1).Menganalisis bagaimana perubahan pemanfaatan ruang di wilayah Sub DAS Expo. 2).Menganalisis akibat perubahan pemanfaatan ruang terhadap ketersediaan air aktual di wilayah Sub DAS Expo.3).Memberikan arahan pemanfaatan ruang guna perbaikan ketersediaan air di wilayah Sub DAS Expo. Jenis penelitian adalah analisis deskriptif kuantitatif, menggunakan metode metode analisis spasial Sistem Informasi Geografi (SIG). Hasil yang diperoleh 1) Terdapat perubahan tutupan lahan di Sub DAS Expo berupa penurunan luas area kawasan hutan dan penambahan area pada tanah terbuka dan semak belukar, sedangkan penggunaan lahan untuk pemukiman, perkantoran, komersial dan industri tidak melampaui peruntukan lahan dalam pola ruang.2) Tingkat ketersediaan air di Sub DAS Expo didominasi oleh kelas ketersediaan air. 3) Berdasarkan hasil analisis tutupan lahan aktual dan recana pola ruang, maka arahan pemanfaatan ruang untuk perbaikan tingkat ketersediaan air wilayah Sub DAS Expo, yaitu (1) lahan yang dirubah kondisinya menjadi vegetasi permanen, (2) lahan yang diupayakkan menerapkan konsep agroforestry, (3) lahan dengan KDB/RTH $40 \%$ dan RTH 60\%, (4) lahan RTH minimal 20\% dengan sumur resapan, dan (5) lahan sempadan dan konservasi; dan di Distrik Jayapura Selatan dan Jayapura Utara
\end{abstract}

Kata Kunci: Pemanfaatan Ruang, Ketersediaan Air, Daerah Aliran Sungai (DAS)

\begin{abstract}
Space as a place where humans operate, should be managed and put to good use. The use of space in accordance with the carrying capacity, will create a balance and preservation of the environment. The utilization of the Expo Subwatershed space through optimal land use efforts is needed to maintain the sustainability of existing ecosystems, and maintain environmental quality, and maintain a balance between community activities and the environment in the Expo Subwatershed. Problem Formulation "How is the influence of spatial utilization on the actual conditions of water availability in the Expo Sub-watershed?" While the research objectives are 1). Analyzing how changes in spatial use in the Expo Subwatershed area. 2). Analyzing due to changes in the use of space to the availability of actual water in the Sub-watershed area of Expo.3) Providing directions for spatial use to improve water availability in the Expo Sub-watershed area. This type of research is quantitative descriptive analysis, using the method of spatial analysis of Geographic Information Systems (GIS). Results obtained 1) There is a change in land cover in the Expo Sub-watershed in the form of a decrease in the area of the forest area and the addition of open land and shrubs, while the use of land for settlements, offices, commercial and industrial areas does not exceed land use. The level of water availability in the Expo Sub-watershed is dominated by water availability classes. 3) Based on the results of the actual land cover analysis and the reconciliation of spatial patterns, the direction of spatial use to improve the water availability level of the Expo DAS area, namely (1) the land changed to permanent vegetation, (2) land cultivated using the concept of agroforestry, (3) land with KDB / RTH 40\% and RTH 60\%, (4) RTH land with a minimum of $20 \%$ with infiltration wells, and (5) border area and conservation; and in the District of South Jayapura and North Jayapura.
\end{abstract}

Keywords: Space Utilization, Water Availability, Watershed Area

\section{Pendahuluan}

Ketersediaan Air di dunia rata-rata adalah 7.600 $\mathrm{m} 3$ perkapita/tahun. Indonesia memiliki Indeks ketersediaan. Air yang cukup tinggi yaitu 16,8 m3/kapita/tahun, berdasarkan wilayah, Pulau Jawa memiliki Indeks Ketersediaan Air yang rendah 1.600 m3/perkapita/tahun sedangkan pulau Papua dan Maluku yang tertinggi dengan Indeks Ketersediaan Air 250.000 m3/perkapita/tahun (Robert J. Kodatie, et.al. 2001). Secara teoritis Indonesia seharusnya tidak mengalami masalah, pada kenyataannya Indonesia senantiasa dihadapkan pada 
permasalahan krusial terkait ketahanan air. Hal ini disebabkan karena potensi ketersediaan air bersih dari tahun ke tahun cenderung berkurang akibat degradasi daya dukung Daerah Aliran Sungai (DAS) hulu akibat kerusakan hutan yang tidak terkendali (Samekto \& Winata, 2010).

Hutan sebagai salah satu vegetasi permanen dapat berdampak pada terjadinya penambahan atau penurunan kualitas suatu DAS akibat adanya perubahan penutupan lahan. Perubahan penutupan lahan merupakan aktifitas terhadap suatu lahan yang berbeda dari aktifitas sebelumnya, baik untuk tujuan komersial maupun industri. Berbagai aktifitas manusia untuk memenuhi kebutuhannya sebagian besar mengandalkan atau berada diatas lahan. Kegiatan tata guna lahan yang bersifat mengubah bentang lahan dalam suatu wilay ah misalnya DAS seringkali dapat mempengaruhi hasil air. Perubahan luas tutupan lahan mempengaruhi jumlah ketersediaan air (Erlangga, 2013).

Air merupakan determinan dalam pengaturan fungsi lindung dan budidaya dalam penataan ruang. Ruang dan sumber daya alam yang terbatas harus menjadi batas optimal bagi pengembangan kegiatan budidaya, dalam tata ruang tidak di toleransikan adanya pengembangan kegiatan budidaya yang melebihi kapasitas dukung ruang dan sumber daya alam yang tersedia (Sujana Royat, 1999).

Air sebagai salah satu sumber daya alam yang perlu didayagunakan dan ditingkatkan hasil gunanya untuk kepentingan pembangunan dan kebutuhan masyarakat sehingga air perlu di kelola dengan tujuan untuk meningkatkan efisiensi dan efektifitasnya mendukung berbagai kegiatan pembangunan.

Wilayah merupakan ruang pada permukaan bumi, yaitu suatu tempat atau lokasi yang dilihat secara vertikal dan horizontal. Di dalamnya termasuk apa yang ada di permukaan bumi, yang ada di bawah permukaan bumi dan yang ada di atas permukaan bumi. Menurut Glasson ada dua cara pandang berbeda tentang wilayah yaitu subyektif dan obyektif (Tarigan, 2010).

Cara pandang subyektif yaitu wilayah adalah alat untuk mengidentifikasi suatu lokasi yang didasarkan atas kriteria tertentu atau tujuan tertentu. Dengan demikian banyaknya wilayah tergantung kepada kriteria yang digunakan. Wilayah hanyalah model agar kita bisa membedakan lokasi yang satu dangan lokasi lainnya. Sedangkan pandangan obyektif menyatakan wilayah itu benar-benar ada dan dapat dibedakan dari ciri-ciri atau gejala alam dI setiap wilayah. Wilayah bisa di bedakan menurut musim atau temperatur yang dimilikinya atau konfigurasi lahan, jenis tumbuh-tumbuhan, kepadatan penduduk atau gabungan dari ciri-ciri tersebut. Menggunakan pandangan obyektif membuat jenis analisis terhadap ruang menjadi terbatas. Dengan melakukan pengamatan seksama, perhitungan dan bantuan peralatan tertentu suatu wilayah dapat diidentifikasi dengan tepat, bisa digambarkan melalui peta. Menurut Hanafiah (1982), unsur-unsur ruang yang terpenting adalah : Jarak, Lokasi, Bentuk, Ukuran atau skala. Setiap wilayah harus memiliki keempat unsur tersebut, secara bersama-sama keempat unsur itu membentuk suatu unit ruang yang disebut wilayah yang dapat dibedakan dari wilayah lain.

Selanjutnyan menurut Glasson wilayah dapat dibedakan berdasarkan kondisinya atau berdasarkan fungsinya. Berdasarkan kondisinya wilayah dapat dikelompokkan atas keseragaman isinya (homogenity), sedangkan berdasakan fungsinya dapat berbentuk orde, hierarki, lokasi produksi dan sebagainya.

Berkaitan dengan hal tersebut, peranan tata ruang yang pada hakekatnya dimaksudkan untuk mencapai pemanfaatan sumber daya optimal dengan sedapat mungkin menghindari konflik pemanfaatan sumber daya, dapat mencegah timbulnya kerusakan lingkungan hidup serta meningkatkan keselarasan. Menurut Undang-undang No. 26 Tahun 2007 tentang Penataan Ruang, pola ruang adalah distribusi peruntukan ruang dalam suatu wilayah yang meliputi peruntukan ruang untuk fungsi lindung dan peruntukan ruang untuk fungsi budidaya. Konsep pola pemanfaatan ruang wilayah menunjukan bentuk hubungan antara berbagai aspek sumberdaya manusia, sumberdaya alam, sumberdaya buatan, sosial budaya, ekonomi, teknologi, informasi, administasi, pertahanan keamanan, fungsi lindung, budidaya dan estetika lingkungan, dimensi ruang dan waktu yang dalam kesatuan secara utuh dan menyeluruh serta berkualitas membentuk tata ruang (Nurhaeny, 2012). Pertimbangan dalam perencanaan pola pemanfaatan ruang wilayah adalah dinamika perkembangan wilayah, kebijakan pembangunan, potensi unggulan, optimalisasi ruang untuk kegiatan, kapasitas serta daya dukung sumber daya. Pola pemanfaatan ruang wilayah terdiri dari arahan pengelolaan kawasan lindung, arahan pengelolaan kawasan budidaya, kawasan perkotaan dan pedesaan serta kawasan prioritas (Rustiadi. et.al, 2004).

Perubahan penggunaan lahan secara langsung menyebabkan perubahan tutupan lahan. Perubahan penutupan lahan diartikan sebagai suatu proses perubahan dari penutupan lahan sebelumnya ke penutupan lain yang bersifat permanen maupun sementara dan merupakan konsekuensi logis dari adanya pertumbuhan dan transformasi perubahan struktur sosial ekonomi masyarakat yang sedang berkembang baik untuk tujuan komersial maupun industri.

Berdasarkan sistem siklus air, dapat di ketahui bahwa air yang berada di bumi ini merupakan hasil dari hujan (presipitasi). Air hujan di permukaan bumi jatuh di berbagai kondisi tutupan lahan, baik itu perkotaan, desa, hutan, sawah, jenis tanah yang berbeda dan topografi yang berbeda. Kondisi lahan yang berbeda akan membedakan besarnya air yang akan mengalami peresapan ke dalam tanah, penguapan, tersimpan di tajuk-tajuk pohon dan cekungan, maupun menjadi aliran langsung. Kondisi tersebut menunjukkan bahwa komponen fisik dan meteorologis memiliki pengaruh terhadap ketersediaan air (kondisi hidrologi) di suatu DAS.

Ketersediaan air adalah jumlah air yang diperkirakan terus menerus ada disuatu lokasi dengan jumlah tertentu dan dalam jangka waktu tertentu. Ketersediaan air dalam pengertian sumberdaya air pada dasarnya berasal dari air hujan, air permukaan dan air tanah. Hujan yang jatuh diatas permukaan pada suatu daerah aliran sungai atau wilayah sungai sebagian akan menguap kembali sesuai dengan proses iklimnya, sebagian akan mengalir melalui permukaan dan sub permukaan masuk ke dalam saluran, sungai atau danau dan sebagian lagi akan meresap jatuh ke tanah sebagai pengisian kembali pada kandungan air tanah yang ada (Bappenas, 2006).

Ketersediaan air permukaan dari waktu ke waktu relatif tetap sesuai dengan siklus hidrologi, namun keadaan dan sifat kualitasnya dapat membatasi pemakaian dan 
pemanfaatan. Di samping itu kebutuhan air pada saat ini dan pada masa yang mendatang akan terus meningkat sementara ketersediaan air permukaan dan air tanah relatif tetap bahkan mungkin dapat berkurang.

Daerah Aliran Sungai merupakan suatu wilayah daratan yang terwujud sebagai suatu kesatuan dengan sungai dan anak-anak sungainya, yang berfungsi menyimpan dan mengalirkan air yang berasal dari curah hujan ke danau atau ke laut secara alami, yang batas di darat merupakan pemisah topografis dan batas di laut sampai dengan perairan yang masih terpengaruh aktifitas daratan. Atas pemahaman konsep tersebut dapat dikatakan bahwa DAS merupakan satuan ekologis yang terpisah dengan satuan lainnya oleh batas alami. DAS merupakan region tempat berlangsungnya proses hidrologis (Rudi P. Tambunan, 2005).

Wilayah daratan tersebut dinamakan daerah tangkapan air (DTA atau catchment area) yang merupakan suatu ekosistem dengan unsur utamanya terdiri atas sumberdaya alam (tanah, air, dan vegetasi) dan sumberdaya manusia sebagai pemanfaat sumberdaya alam (Asdak, 2010). Sedangkan Soemarto (1987) mengatakan bahwa DAS adalah suatu sistem yang mengubah curah hujan (input) ke dalam debit (output) dipelepasannya (outlet).

Secara umum suatu DAS dibagi dalam tiga wilayah, yaitu wilayah hulu, wilayah tengah dan wilayah hilir. Ketiga wilayah tersebut memiliki karakteristik dan fungsi berbeda, yaitu (Kementerian Kehutanan, 2013) : 1)DAS Bagian Hulu didefinisikan sebagai daerah aliran yang terbatas pada bagian hulu dimana $>70 \%$ dari permukaan lahan DAS tersebut umumnya mempunyai kemiringan lahan $>8 \%$. Disini, aspek prioritas pemanfaatan lahan adalah konservasi tanah dan pengendalian erosi. Secara hidrologis, DAS bagian hulu biasanya membentuk daerah utama pengisian kembali curah hujan untuk air permukaan dan air tanah dari DAS, 2) DAS Bagian Tengah didefinisikan sebagai daerah aliran yang terbatas pada bagian tengah, dimana kurang lebih $50 \%$ dari permukaan lahan DAS tersebut mempunyai kemiringan lahan $<8 \%$ serta dimana baik konservasi tanah maupun pengendalian banjir adalah sama pentingnya. Secara hidrologis DAS bagian tengah membentuk daerah utama transisi curah hujan untuk air tanah, dan 3)DAS Bagian Hilir didefinisikan sebagai daerah aliran yang terbatas pada bagian hilir, dimana kurang lebih $70 \%$ permukaan lahannya mempunyai kemiringan $<8 \%$. Disini, pengendalian banjir dan drainage biasanya merupakan faktor-faktor yang terabaikan dalam pengembangan tata guna lahan.

DAS merupakan sistem yang kompleks dan heterogen yang terdiri dari beberapa sub sistem, dimana sub sistem tersebut dianggap homogeni. Sebagai suatu ekosistem, DAS merupakan kesatuan berbagai sub-sistem yang didalamnya terdapat berbagai interaksi ekologi, ekonomi, dan sosial.

Sehingga dalam konteks seperti itu, DAS merupakan suatu unit pengelolaan (management unit) dimana pemanfaatan sumberdaya hutan, lahan, dan air diarahkan untuk dapat memberikan manfaat secara ekologis, ekonomi dan sosial (Baja, 2012).

Pengelolaan DAS di sini dapat diartikan sebagai suatu bentuk pengembangan wilayah yang menempatkan DAS sebagai unit pengelolaannya, yang pada dasarnya merupakan usaha-usaha penggunaan sumberdaya alam (hutan, tanah, dan air) di suatu DAS secara rasional untuk mencapai tujuan ekonomi (produksi) sumberdaya lahan yang optimum dan berkelanjutan, disertai dengan upayaupaya untuk menekan kerusakan seminimal mungkin, melalui konservasi tanah dan air. Untuk itu, diperlukan perencanaan tata guna lahan secara baik, dan karena kompleksnya karakteristik DAS, maka dibutuhkan dukungan pemodelan spasial dalam upaya membantu perencanaan secara efektif (Baja, 2012).Berkaitan dengan hal tersebut, peranan tata ruang yang pada hakekatnya dimaksudkan untuk mencapai pemanfaatan sumber daya optimal dengan sedapat mungkin menghindari konflik pemanfaatan sumber daya, dapat mencegah timbulnya kerusakan lingkungan hidup serta meningkatkan keselarasan.

Pertimbangan dalam perencanaan pola pemanfaatan ruang wilayah adalah dinamika perkembangan wilayah, kebijakan pembangunan, potensi unggulan, optimalisasi ruang untuk kegiatan, kapasitas serta daya dukung sumber daya. Pola pemanfaatan ruang wilayah terdiri dari arahan pengelolaan kawasan lindung, arahan pengelolaan kawasan budidaya, kawasan perkotaan dan pedesaan serta kawasan prioritas (Rustiadi. et.al, 2004).

Tujuan penelitian ini adalah untuk menganalisis bagaimana perubahan pemanfaatan ruang di wilayah Sub DAS Expo.

\section{Metode Penelitian}

Metode yang digunakan untuk penelitian ini adalah deskriptif kuantitatif. Menurut Tika (2005) penelitian deskriptif merupakan penelitian yang lebih mengarah pada pengungkapan suatu masalah atau keadaan sebagaimana adanya dan mengungkapkan fakta-fakta yang ada, walaupun kadang-kadang diberikan interpretasi atau analisis. Sedangkan kuantitatif adalah pendekatan yang menekankan pada hal-hal yang bersifat konkret, uji empiris dan fakta-fakta yang nyata dengan menggunakan angkaangka. sedangkan metode penelitian ini adalah metode analisis spasial Sistem Informasi Geografi (SIG).

Data pada masing-masing obyek penelitian diukur dan dipilih berdasarkan satuan wilayah ekologi dengan tetap mempertimbangkan wilayah DAS sebagai batas ekosistem. Selanjutnya data dianalisis secara kuantitatif untuk mendapatkan gambaran secara nyata tentang nilai dan persebaran (spasial) kondisi pemanfaatan ruang dan ketersediaan air di Sub DAS Expo.

Data-data yang diperoleh baik data primer maupun data sekunder langsung dianalisis secara interpretative dan kuantitatif dengan merujuk pada referensi yang ada (studi pustaka).

Variabel penelitian pada dasarnya adalah kondisikondisi atau serenteristik-serenteristik yang oleh peneliti dimanipulasikan, di kontrol atau diobservasi dalam suatu penelitian. Menurut Direktorat Pendidikan Tinggi Depdikbud, variabel penelitian adalah segala sesuatu yang akan menjadi obyek pengamatan penelitian. Variabel penelitian meliputi faktor-faktor yang berperan dalam peristiwa atau gejala yang akan di teliti. (Cholid Narbuko, 
2004). Variabel yang di amati dalam penelitian ini terdiri dari :

1. Variabel Independen (variabel bebas). Variabel yang memperlihatkan kondisi-kondisi atau karateristikkarateristik yang oleh peneliti dimanipulasi dalam rangka menerangkan hubungannya dengan fenomena yang diobservasi. Fungsi variabel ini sering disebut dengan variable pengaruh sebab fungsinya mempengaruhi variabel lain.

2. Variabel dependen (variabel terpengaruh). Variabel yang mempelihatkan kondisi atau karateristik yang berubah atau muncul ketika peneliti mengintroduksi, pengubah atau mengganti variabel bebas, menurut fungsinya variabel ini dipengaruhi oleh variable lain.

Dalam penelitian ini, terdapat tiga variabel yang terdiri dari dua variabel independen dan satu variabel dependen. Variabel independen dalam penelitian ini adalah Pola Ruang dan Penggunaan Lahan wilayah Sub DAS Expo Sedangkan variabel dependen pada penelitian ini adalah Ketersediaan Air. Seluruh variabel dalam penelitian ini diukur dengan menggunakan sistem informasi geografis (SIG).

Menurut Sugiyono (2010), analisis data adalah proses mencari dan menyusun secara sistematis data yang diperoleh dari hasil wawancara, catatan lapangan dan dokumentasi dengan cara mengorganisasikan data dalam kategori, menjabarkan ke dalam unit-unit, melakukan sintesa, menyusun ke dalam pola, memilih mana yang penting dan yang akan dipelajari, dan membuat kesimpulan sehingga mudah dipahami oleh diri sendiri dan orang lain.

Pada penelitian ini teknik analisis data yang digunakan yaitu :

a. Analisis SIG dengan overlay peta tematik

Teknik analisis data digital dengan melakukan overlay peta-peta tematik berupa peta pola ruang, penggunaan lahan, peta wilayah DAS, topografi, tanah dan ketersediaan air periode 2006 -2015 untuk wilayah Sub DAS Expo menggunakan aplikasi Sistem Informasi Geografi (SIG) software ArcGIS 10.3. Data yang akan di analisis dikelompokkan ke dalam tipe data spasial dan data teks (tabular). Tahapan ini terdiri dari penyiapan data berupa data spasial dan data atribut untuk menghasilkan output sesuai dengan tujuan penelitian.

b. Tingkat Ketersediaan Air

Adapun nilai interval ketersediaan air diperoleh dengan menggunakan rumus interval Sturgess yaitu membagi nilai data tertinggi dan data terendah sehingga sesuai dengan kelas yang diinginkan, rumus interval Sturgess :

$$
\mathrm{Ki}=(\mathrm{Xt}-\mathrm{Xr}) / \mathrm{k}
$$

Keterangan:

$$
\begin{aligned}
& \mathrm{Ki}=\text { Kelas Interval } \\
& \mathrm{Xr}=\text { Data terendah } \\
& \mathrm{Xt}=\text { Data Tertinggi } \\
& \mathrm{k}=\text { Jumlah kelas yang diinginkan } \\
& \text { Sumber: Hendriana, } 2013 .
\end{aligned}
$$

Masing - masing nilai kelas Interval (Ki) untuk Ketersediaan Air Aktual (2006 - 2015) dan Ketersediaan Air berdasarkan Pola Ruang di Sub DAS Expo, disajikan pada Tabel 1. dan Tabel 2.
Tabel 1. Kelas Ketersediaan Air Aktual Sub DAS Expo

\begin{tabular}{crc}
\hline \multirow{2}{*}{ Kelas } & \multicolumn{2}{c}{ Nilai Ketersediaan Air } \\
\cline { 2 - 3 } & $\begin{array}{c}\text { Min. } \\
\left(\mathbf{m}^{\mathbf{3}}\right)\end{array}$ & $\begin{array}{c}\text { Maks. } \\
\left(\mathbf{m}^{\mathbf{3}}\right)\end{array}$ \\
\hline Rendah & 964.594 .200 & 1.093 .347 .300 \\
Sedang & 1.093 .347 .301 & 1.169 .007 .000 \\
Tinggi & 1.169 .007 .001 & 1.304 .531 .667 \\
\hline
\end{tabular}

Sumber : Data diolah, 2017.

Tabel 2. Kelas Ketersediaan Air Pola Ruang Sub DAS Expo

\begin{tabular}{ccc}
\hline \multirow{2}{*}{ Kelas } & \multicolumn{2}{c}{ Nilai Ketersediaan Air } \\
\cline { 2 - 3 } & $\begin{array}{c}\text { Min. } \\
\left(\mathbf{m}^{3}\right)\end{array}$ & $\begin{array}{c}\text { Maks. } \\
\left(\mathbf{m}^{3}\right)\end{array}$ \\
\hline Rendah & 1.040 .689 .500 & 1.156 .250 .111 \\
Sedang & 1.156 .250 .112 & 1.228 .370 .667 \\
Tinggi & 1.228 .370 .668 & 1.321 .776 .556 \\
\hline
\end{tabular}

Sumber : Data diolah, 2017.

\section{c. Arahan Tutupan Lahan Sub DAS Expo}

Untuk analisis data pemanfaatan ruang di sekitar Sub DAS Expo dilakukan dengan pendekatan pembuatan arahan perbaikan tutupan lahan untuk memperbaiki tingkat

\begin{tabular}{|c|c|c|}
\hline No & Penutupan Lahan & Arahan \\
\hline 1 & $\begin{array}{l}\text { Lahan dengan Tutupan } \\
\text { Hutan }\end{array}$ & $\begin{array}{l}\text { Dipertahankan kondisinya } \\
\text { agar tetap berhutan }\end{array}$ \\
\hline 2 & $\begin{array}{l}\text { Arahan Pola Ruang } \\
\text { Kawasan Hutan tetapi } \\
\text { Kondisi bukan Hutan }\end{array}$ & $\begin{array}{l}\text { Diubah Kondisinya Menjadi } \\
\text { Vegetasi Permanen } \\
\text { (Rehabilitasi) }\end{array}$ \\
\hline 3 & $\begin{array}{l}\text { Arahan Pola Ruang } \\
\text { Kawasan Hutan tetapi } \\
\text { telah berkembang } \\
\text { menjadi Lahan } \\
\text { Pertanian }\end{array}$ & $\begin{array}{l}\text { Diupayakan menerapkan } \\
\text { konsep Agroforestry (Social } \\
\text { Forestry) }\end{array}$ \\
\hline 4 & $\begin{array}{l}\text { Status Pola Ruang } \\
\text { bukan Kawasan Hutan } \\
\text { tapi merupakan Lahan } \\
\text { Terbangun }\end{array}$ & $\begin{array}{l}\text { Kawasan dengan KDB } \\
(40 \%) \text { dan RTH }(60 \%)\end{array}$ \\
\hline 5 & $\begin{array}{l}\text { Kawasan Publik } \\
\text { (Perdagangan, } \\
\text { Perkantoran, } \\
\text { Pendidikan, Bisnis) }\end{array}$ & $\begin{array}{l}\text { Diusakan ada RTH (Min } \\
20 \% \text { ) di dalam kawasan } \\
\text { tersebut dan dilengkapi } \\
\text { dengan sumur resapan }\end{array}$ \\
\hline 6 & $\begin{array}{l}\text { Arahan Pola Ruang } \\
\text { untuk Pertanian }\end{array}$ & $\begin{array}{l}\text { Tetap dipertahankan sebagai } \\
\text { Lahan Pertanian dengan } \\
\text { menerapkan Teknik KTA }\end{array}$ \\
\hline 7 & $\begin{array}{l}\text { Kawasan Sempadan dan } \\
\text { Kawasan Konservasi }\end{array}$ & $\begin{array}{l}\text { Mengikuti aturan-aturan } \\
\text { yang berlaku }\end{array}$ \\
\hline
\end{tabular}
ketersediaan air dan diarahkan ke pengelolaan yang mampu menyediakan suplai air secara berkelanjutan di wilayah Sub DAS Expo. Kriteria yang digunakan dalam arahan perbaikan tutupan lahan, disajikan pada Tabel 3.

Tabel 3. Kriteria Arahan Penutupan Lahan

Sumber : P3E Papua - KLHK, 2017

\section{d. Anailisis Deskriptif}

Analisis deskriptif digunakan untuk menjelaskan data hasil analisis pemanfaatan ruang dan ketersediaan air. Hasil temuan dari penelitian tersebut antara lain luas perubahan tutupan lahan dan tingkat ketersediaan air serta 
arahan perbaikan penutupan lahan di wilayah Sub DAS Expo.

\section{Hasil dan Pembahasan}

Rencana Tata Ruang Wilayah (RTRW) Kota Jayapura, alokasi peruntukan ruang di Sub DAS Expo pada rencana pola ruang terdiri dari kawasan lindung dan kawasan budidaya yang teralokasi kawasan lindung seluas $2.731,88$ hektar $86,59 \%$ dan kawasan budidaya 422,93 hektar atau 13,41\% dari luas DAS Expo. Alokasi pemanfaatan ruang kawasan lindung berdasarkan rencana pola ruang, disajikan pada Tabel 4. Sedangkan peruntukan kawasan budidaya dalam pola ruang terdiri dari 13 peruntukan lahan, disajikan pada Tabel 5. Berdasarkan Tabel 5, peruntukan lahan kawasan budidaya di Sub DAS Expo terbagi atas kawasan resapan air seluas 291,91 hektar atau 9,25\% dari luas Sub DAS Expo, atau 7,44\% dari luas Sub DAS Expo, RTH Perlindungan setempat seluas 80,44 hektar atau seluas 2,55\% dari luas Sub DAS Expo dan hutan produksi untuk konversi seluas 66,49 hektar atau 2,11\% dari luas Sub DAS Expo.

Peruntukan ruang kawasan lindung dan budidaya di Sub DAS Expo berdasarkan rencana pola ruang Kota Jayapura, (Gambar 1)

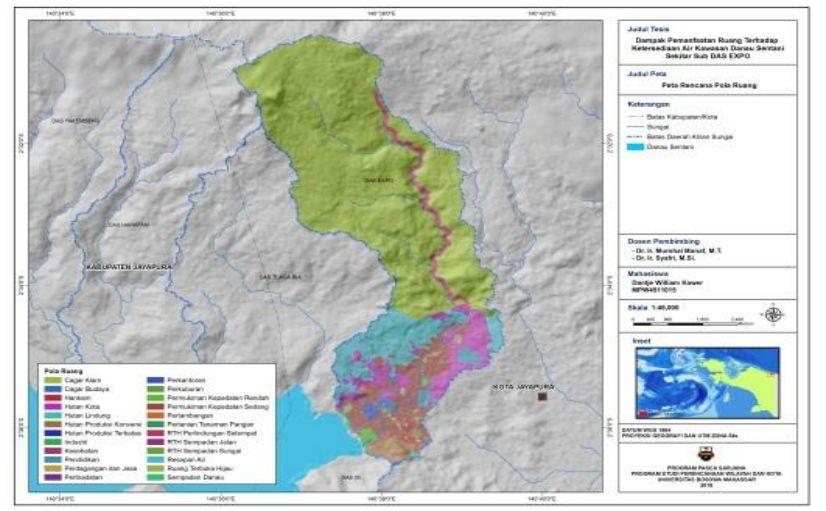

Gambar 1. Peta Pola Ruang di Sub DAS Expo

Tabel 4. Alokasi Ruang Kawasan Lindung di Sub DAS Expo

\begin{tabular}{llrc}
\hline No & \multicolumn{1}{c}{ Pola Ruang } & Luas (ha) & Persentase (\%) \\
\hline 1 & Cagar Alam & $2,105,89$ & 66,75 \\
2 & Cagar Budaya & 10,42 & 0,33 \\
3 & Hutan Kota & 212,17 & 6,73 \\
4 & Hutan Lindung & 2,76 & 0,09 \\
5 & Resapan Air & 291,91 & 9,25 \\
6 & RTH Perlindungan & 80,44 & 2,55 \\
& Setempat & & \\
7 & RTH Sempadan Jalan & 1,14 & 0,04 \\
8 & RTH Sempadan Sungai & 6,00 & 0,19 \\
9 & Ruang Terbuka Hijau & 13,41 & 0,43 \\
10 & Sempadan Danau & 7,74 & 0,25 \\
\hline \multicolumn{2}{r}{ Total } & $\mathbf{2 . 7 3 1 , 8 8}$ & $\mathbf{8 6 , 5 9}$ \\
\hline
\end{tabular}

Sumber : Analisis SIG, 2017.

Tabel 5. Alokasi Ruang Kawasan Budidaya di Sub DAS Expo

\begin{tabular}{ccrr}
\hline No & Pola Ruang & Luas (ha) & Persen (\%) \\
\hline 1 & Hutan Produksi Konversi & 66,49 & 2,11 \\
2 & Hutan Produksi Terbatas & 2,06 & 0,07
\end{tabular}

\begin{tabular}{clrr}
3 & Hankam & 15,50 & 0,49 \\
4 & Industri & 4,33 & 0,14 \\
5 & Kesehatan & 3,39 & 0,11 \\
6 & Pendidikan & 46,01 & 1,46 \\
7 & Perdagangan dan Jasa & 12,72 & 0,40 \\
8 & Peribadatan & 3,31 & 0,10 \\
9 & Perkantoran & 18,43 & 0,58 \\
10 & Perkuburan & 1,54 & 0,05 \\
11 & Permukiman Kepadatan Rendah & 10,84 & 0,34 \\
12 & Permukiman Kepadatan Sedang & 234,86 & 7,44 \\
13 & Pertambangan & 3,45 & 0,11 \\
\hline \multicolumn{2}{c}{ Total } & $\mathbf{4 2 2 , 9 3}$ & $\mathbf{1 3 , 4 1}$ \\
\hline
\end{tabular}

Sumber: Analisis SIG, 2017.

Berdasarkan data tutupan lahan tahun 2015, terdapat 7 kategori tutupan lahan terdiri dari hutan lahan kering primer, hutan lahan kering sekunder, permukiman, pertanian lahan kering campur semak, semak belukar, tanah terbuka, tubuh air. Jenis penutupan lahan, disajikan pada Tabel 6.

Tabel 6. Penutupan Lahan Sub DAS Expo Tahun 2015

\begin{tabular}{c|l|c|c}
\hline No & \multicolumn{1}{|c|}{ Penutupan Lahan } & Luas (ha) & $\begin{array}{c}\text { Persen } \\
(\boldsymbol{\%})\end{array}$ \\
\hline 1 & Hutan Lahan Kering Primer & $1.753,32$ & 55,60 \\
2 & Hutan Lahan Kering & 302,76 & 9,60 \\
& Sekunder & 283,18 & \\
3 & Permukiman & 200,45 & 6,98 \\
4 & Pertanian Lahan Kering & & \\
& Campur Semak & 204,76 & 6,49 \\
5 & Semak Belukar & 409,30 & 12,97 \\
7 & Tanah Terbuka & 0,04 & 0,001 \\
\hline \multicolumn{2}{|c|}{ Total } & $\mathbf{3 , 1 5 3 . 8 1}$ & $\mathbf{1 0 0 . 0 0}$ \\
\hline
\end{tabular}

Sumber: Analisis SIG, 2017.

Dari tutupan lahan tersebut Sub DAS Expo masih di dominasi kawasan hutan seluas 2.057,09 hektar atau.65,21\% dari luas tutupan lahan. Berdasarkan Tabel 6, penutupan lahan hutan lahan kering seluas 1.753,32 hektar atau 55,60\% dari luas Sub DAS Expo, hutan lahan kering sekunder seluas 302,76 hektar atau $9,60 \%$ dari luas DAS Expo, pemukiman seluas 283,18 hektar atau 8,98\% dari luas DAS Expo, pertanian lahan kering campur semak seluas 200,45 hektar atau 6.35\% dari luas Sub DAS Expo, semak belukar seluas 204,76 hektar atau 6,49\% dari luas Sub DAS Expo, tanah terbuka seluas 409.30 hektar atau $12,97 \%$ dari luas Sub DAS Expo, tubuh air seluas 0,04 hektar atau 0,001\% dari luas Sub DAS Expo. atau 12,97\% dari luas Sub DAS Expo, tubuh air seluas 0,04 hektar atau 0,001\% dari luas Sub DAS Expo.

Alokasi ruang kawasan hutan, pemukiman, kantor, komersial, tanah terbuka dan tubuh air, dimana terjadi pengurangan luas lahan kawasan hutan. Dari hasil analisis data rencana pola ruang Kota Jayapura dan kondisi tutupan lahan tahun 2015 di Sub DAS Expo, terdapat perubahan dalam hutan dan terjadi peningkatan lahan semak belukar dan tanah terbuka, perubahan pemanfaatan ruang di Sub DAS Expo, disajikan pada Tabel 7.

Tabel 7. Perubahan Pemanfaatan Ruang Sub DAS Expo

\begin{tabular}{ccccc}
\hline No. & $\begin{array}{c}\text { Kategori } \\
\text { Penutupan } \\
\text { Lahan }\end{array}$ & Pola Ruang & $\begin{array}{c}\text { Pola } \\
\text { Ruang }\end{array}$ & $\begin{array}{c}\text { Peruntukan Lahan (ha) } \\
\text { Lahan (ha) }\end{array}$ \\
\cline { 3 - 4 } & Hutan & $2.790,01$ & $2.257,58$ & $(532,43)$ \\
2 & Semak belukar & 0 & 204.76 & 204,76
\end{tabular}




\begin{tabular}{llccc}
\hline 3 & $\begin{array}{l}\text { Pemukiman, } \\
\text { Kantor, }\end{array}$ & 359.81 & 283,18 & (76.63) \\
Komersial & & & \\
4 & Tanah Terbuka & 5 & 409,30 & 404,30 \\
5 & Tubuh Air & 0 & 0,004 & 0,004 \\
\hline
\end{tabular}

Sumber: Analisis SIG, 2017

Berdasarkan Tabel 7, terdapat pengurangan lahan hutan seluas 532,43 hektar dan penambahan lahan semak belukar seluas 204,76 hektar, tanah terbuka seluas 404,30 hektar sedangkan untuk lahan pemukiman, kantor dan komersial terdapat lahan seluas 76,63 hektar yang belum dimanfaatkan.. Visualisasi tentang penutupan lahan Sub DAS Expo (Gambar. 2).

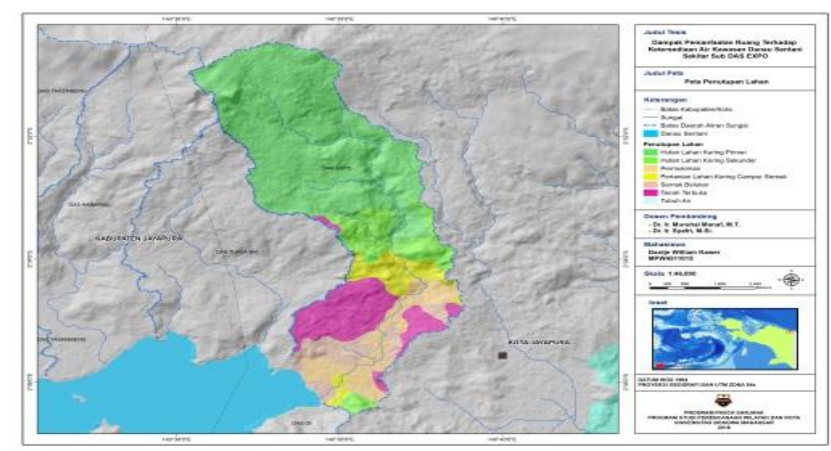

Gambar 2. Peta Pola Ruang di Sub DAS Expo

Daerah Aliran Sungai memberi kontribusi besar dalam ketersediaan air. Faktor pemanfaatan lahan untuk kawasan budidaya di suatu DAS memberi dampak pada ketidakseimbangan sistem hidrologi DAS. Dari hasil analisis kondisi hidrologi DAS di kawasan Danau Sentani tahun 2016, ketersediaan air tahunan di Sub DAS Expo disajikan pada Tabel 8.

Tabel 8. Ketersediaan Air Sub DAS Expo

\begin{tabular}{c|c|c}
\hline \multirow{2}{*}{ Nama DAS } & \multicolumn{2}{|c}{ Ketersediaan Air $\left(\mathrm{m}^{3}\right)$} \\
\cline { 2 - 3 } & $\begin{array}{c}\text { Periode masa lalu } \\
(1987-1996)\end{array}$ & $\begin{array}{c}\text { Periode aktual } \\
(2006-2015)\end{array}$ \\
\hline Sub DAS Expo & $222.193 .213,10$ & $191.712 .853,95$ \\
\hline
\end{tabular}

Sumber: Papua - KLHK, data diolah, 2017

Bedasarkan Tabel 8, ketersediaan air rata-rata di sub DAS Expo pada periode 1987 - 1996 adalah sebesar 222.193.213,10 $\mathrm{m}^{3}$ dan pada periode 2006 - 2015 sebesar 191.712.853,95 m3 kondisi ini memperlihatkan adanya perubahan ketersediaan air di Sub DAS Expo sebesar 30.480.359,16 m3. Kondisi fluktuasi ketersediaan air periode sepuluh tahunan pada unit DAS di Sub DAS Expo (Gambar 3.) Grafik Ketersediaan Air Sub DAS Expo periode 1987 - 1996 dan 2006 - 2015.

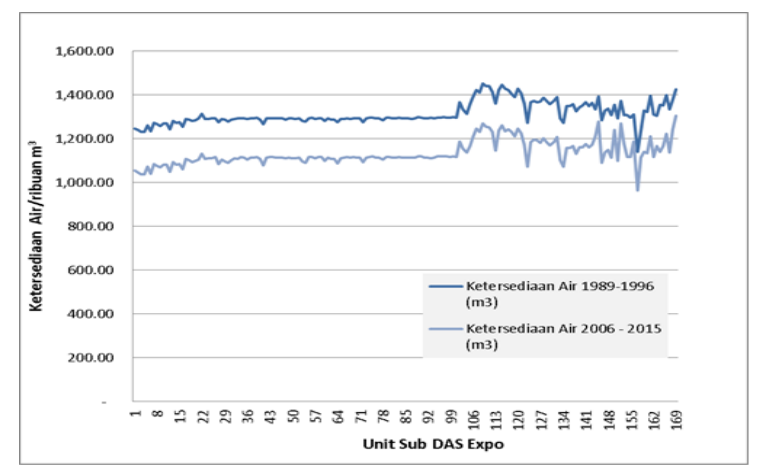

Gambar 3. Grafik Perubahan Ketersediaan Air Sub DAS Expo
Dari Gambar 3, terdapat unit-unit Sub DAS penyuplai air di Sub DAS Expo yang menggambarkan adanya perubahan ketersediaan air periode masa lalu (tahun 1987 - 1996) dengan ketersdiaan air periode aktual (tahun 2006 - 2015), yang dipengaruhi oleh faktor tutupan lahan, kondisi tanah, topografi, kelerengan, iklim dan intensitas curah hujan. Dengan menggunakan persentase neraca ketersediaan air pada periode 1987 - 1996 dan periode 2006 - 2015,terdapat peningkatan (surplus) dan juga penurunan (defisit) ketersediaan air di beberapa area, seperti disajikan pada Tabel 9.

Tabel 9. Tingkat Perubahan Ketersediaan Sekitar Sub DAS

\begin{tabular}{|c|c|c|c|}
\hline \multicolumn{4}{|c|}{ Expo } \\
\hline Wilayah & $\begin{array}{c}\text { Luas Area } \\
\text { (ha) }\end{array}$ & $\begin{array}{l}\text { Persentase } \\
\text { Perubahan }\end{array}$ & $\begin{array}{c}\text { Jumlah } \\
\text { Ketersediaan } \\
\text { Air }\left(\mathbf{m}^{\mathbf{3}}\right)\end{array}$ \\
\hline Distrik Abepura & 37,01 & $>0,00 \%$ & $+1.656 .264,00$ \\
\hline Distrik Heram & $\begin{array}{c}0,38 \\
6,34 \\
1.872,10\end{array}$ & $\begin{array}{c}<0,00 \mathrm{sd}-5 \% \\
<-5 \mathrm{sd}-10 \% \\
>0,00 \%\end{array}$ & $\begin{array}{c}-159.744,00 \\
-748.236,00 \\
+26.673 .266,16\end{array}$ \\
\hline $\begin{array}{l}\text { Distrik } \\
\text { Jayapura } \\
\text { Selatan }\end{array}$ & $1.238,98$ & $>0,00 \%$ & $+11.549 .880,00$ \\
\hline $\begin{array}{l}\text { Distrik } \\
\text { Jayapura Utara }\end{array}$ & 295,82 & $>0,00 \%$ & $+1.903 .929,00$ \\
\hline Total & $3.154,81$ & & $30.480 .359,16$ \\
\hline
\end{tabular}

Keterangan:

+ Surplus Ketersediaan Air

- Defisit Ketersediaan Air

Sumber : P3E Papua - KLHK data diolah, 2017

Berdasarkan Tabel 9. di wilayah Distrik Heram terdapat surplus ketersediaan air (> 0,00\%) sebesar 26.673.266,16 m3 pada area seluas $1.872,10$ hektar dan defisit ketersediaan air $(<00,00 \%$ s/d $-10,00 \%)$ sebesar 907.980,00 m3, pada area seluas 6,72 hektar, di wilayah Distrik Abepura terdapat surplus ketersediaan air (> $0,00 \%$ ) sebesar 1.656.264,00 m3 pada area seluas 37,01 hektar, di wilayah Distrik Jayapura Utara terdapat surplus ketersediaan air $(>0,00 \%)$ sebesar $11.549 .880,00 \mathrm{~m} 3$ pada area seluas 1.238,98 hektar dan di wilayah Distrik Jayapura Utara terdapat surplus air (>0,00\%) sebesar 295,82 m3 pada area seluas 11.549.880,00 hektar.

Data yang diperoleh dari hasil analisis ketersediaan air aktual dengan menggunakan data tutupan lahan tahun 2015, menunjukan adanya sebaran ketersediaan air rendah sampai dengan tinggi di Sub DAS Expo periode 2006 - 2015, dapat dilihat pada Tabel 10.

Tabel 10. Tingkat Ketersediaan Air sekitar Sub DAS Expo

\begin{tabular}{l|c|c|c|c}
\hline \multirow{2}{*}{ Wilayah } & \multicolumn{2}{|c|}{ Ketersediaan Air } & \multirow{2}{*}{$\begin{array}{c}\text { Luas } \\
\text { (holum }\end{array}$} & Persen(\%) \\
\cline { 2 - 3 } & Kelas & $\begin{array}{c}\text { Volume } \\
\text { (ribuan } \mathbf{~ m}^{3} /\end{array}$ & \\
\hline Distrik & Sedang & $3.487,66$ & 27,25 & 1,17 \\
Abepura & Tinggi & $2.383,70$ & 9,77 & 1,17 \\
Distrik & Rendah & $4.205,06$ & 12.43 & 2,45 \\
Heram & Sedang & $54.740,29$ & 749.63 & 20,25 \\
Distrik & Tinggi & $45.152,51$ & 820.94 & 27,48 \\
Jayapura & Rendah & $7.479,26$ & 286.19 & 3,12 \\
Selatan & Sedang & $60.455,35$ & 952.79 & 36,16 \\
Distrik & Rendah & $10.490,62$ & 294.50 & 4,71 \\
Jayapura & Sedang & 3.318 .40 & 1.31 & 4,67 \\
Utara & Total & $\mathbf{1 9 1 . 7 1 2 , 8 5}$ & $\mathbf{3 . 1 5 4 , 8 1}$ & $\mathbf{1 0 0 , 0 0}$ \\
\hline
\end{tabular}

Sumber: P3E Papua KLHK, data diolah, 2017

Berdasarkan Tabel 10, tingkat ketersediaan air aktual di Sub DAS Expo (1) tinggi : di Distrik Abepura dan 
Distrik Heram sebesar 47.563.210 m3 pada area seluas 830,70 hektar, (2) sedang di Distrik Abepura, Distrik Heram,

Distrik Jayapura Utara dan Distrik Jayapura Selatan sebesar $122.001 .700 \mathrm{~m} 3$ pada area seluas 1.730,98 hektar, (3) rendah di Distrik Heram, Distrik Jayapura Utara dan Distrik Jayapura Selatan sebesar 22.174.940 m3 pada area seluas 593,13 hektar. Visualisasi spasial tingkat ketersediaan air di Sub DAS Expo, (Gambar 4.)

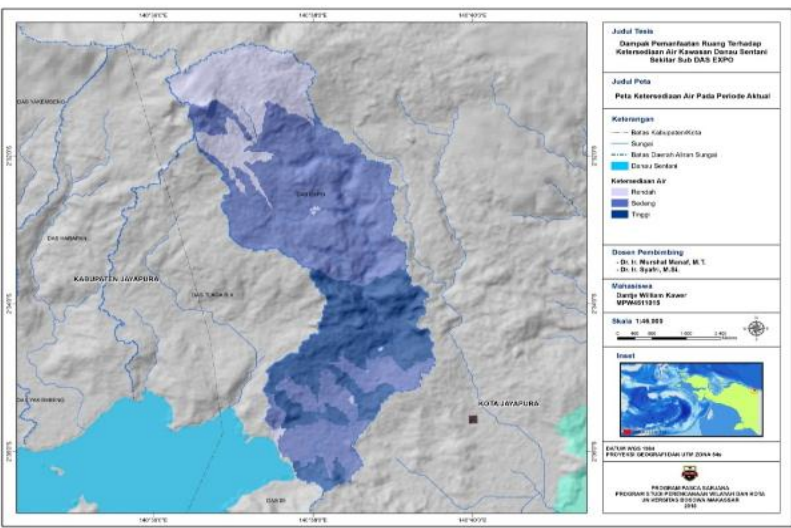

Gambar 4. Peta Ketersediaan Air Aktual Sub DAS Expo Periode 2006 - 2015

\section{Kesimpulan dan Saran}

Hasil penelitian dapat disimpulkan bahwa terdapat perubahan tutupan lahan di Sub DAS Expo berupa penurunan luas area kawasan hutan dan penambahan area pada tanah terbuka dan semak belukar, sedangkan penggunaan lahan untuk pemukiman, perkantoran, komersial dan industri tidak melampaui peruntukan lahan dalam pola ruang.. Tingkat ketersediaan air di Sub DAS Expo didominasi oleh kelas ketersediaan air sedang, dengan kondisi ketersediaan air berdasarkan rencana pola ruang lebih baik dari ketersediaan air periode aktual sehingga pemanfaatan ruang perlu berpedoman kepada rencana pola ruang dalam RTRW Kota Jayapura.

\section{Daftar Pustaka}

Aca Sugandhy. 1999. Penataan Ruang Dalam Pengelolaan Lingkugan Hidup. Jakarta. Penerbit Gramedia.

Asdak, C. 2010. Hidrologi dan Pengelolaan Daerah Aliran Sungai. Yogyakarta: Gadjah Mada University Press.

Badan Pengendalian Dampak Lingkungan Daerah Provinsi Papua dan LPPM-ITB. 2004. Studi Ekosistem Kawasan Danau Sentani.

Badan Standar Nasional. 2010. Klasifikasi Penutupan Lahan. Jakarta: BSNI.

Baja, S. 2012. Perencanaan Tata Guna Lahan dalam Pengembangan Wilayah Pendekatan Spasial \& Aplikasinya. Yogyakarta: Penerbit Andi.

Bappenas, D. P. 2006. Prakarsa Strategis Pengelolaan Sumber Daya Air untuk Mengatasi Banjir dan Kekeringangan di Pulau Jawa. Jakarta: Bappenas.

BPDAS Memberamo. 2015.. Rencana Pengelolaan DAS Sentani, - KLHK. Jayapura..
Cholid Narbuko, H. Abu Achmadi, 2004. Metodologi Penelitian. Jakarta : Penerbit Bumi Aksara.

Ditjen Bina Pengelolaan DAS dan Perhutanan Sosial. KLHK. 2014. Modul Tutorial SWAT : Soil \& Water Assesment Tool. Jakarta..

Ekadinata A., Dewi S, Hadi D, Nugroho D, \& Johana F. 2008. Sistem Informasi Geografis untuk Pengelolaan Bentang Lahan Berbasis Sumber Daya Alam. Buku 1: Sistem Informasi Geografis dan Penginderaan Jauh menggunakan ILWIS Open Source. Bogor: World Agroforestry Centre.

Erlangga, G. 2013. Pengaruh Perubahan Tutupan Lahan Terhadap Ketersediaan Air di DAS Jlantah Hulu Kabupaten Karanganyar

Hadi Sabari Yunus. 2016. Metodologi Penelitian Wilayah Kontemporer. Yogyakarta: Pustaka Pelajar.

Hardjowigeno, S., dan Widiatmaka. 2001. Kesesuaian Lahan dan Perencanaan Tata Guna Tanah. Bogor: Institut Pertanian Bogor.

Hendriana, Ika. 2013. Sistem Informasi Geografis Penentuan Wilayah Rawan Banjir di Kabupaten Buleleng. Denpasar:Universitas Pendidikan Ganesha.

Irwansyah, E. (2013). Sistem Informasi Geografis: Prinsip Dasar dan Pengembangan Aplikasi. Yogyakarta: Penerbit Digibooks.

Kementerian Lingkungan Hidup Republik Indonesia, 2014. Gerakan Penyelamatan Danau (GERMADAN).

Kementerian Kehutanan Republik Indonesia. 2013. Peraturan Dirjen Pengelolaan DAS dan Perhutanan Sosial Nomor : P.3/V-SET/2013 tentang Pedoman Identifikasi Karateristik Daerah Aliran Sungai.

Lutfi Muta'ali. 2015. Teknik Analisis Regional untuk Perencanaan Wilayah, Tata Ruang dan Lingkungan. Yogyakarta : BPFG-UGM.

Mubarok, Z. (2014). Kajian Respons Perubahan Penggunaan Lahan terhadap Karakteristik Hidrologi DAS Way Betung. Bogor: Sekolah Pascasarjana Institut Pertanian Bogor.

Nazir, Moh. 2005. Metode Penelitian. Jakarta: Ghalia Indonesia.

Nurhaeny. 2012. Optimalisasi Pemanfaatan Lahan Kawasan Daerah Aliran Sungai (DAS) Jeneberang Sekitar Waduk Bili-Bili. Makassar : Tesis Program Pascasarjana Universitas 45 Makassar.

Pawitan, H. 2004. Aplikasi Model Erosi dalam Perspektif Pengelolaan DAS. Prosiding Seminar Degradasi Lahan dan Hutan. Masyarakat Konservasi Tanah dan Air Indonesia. Yogyakarta : Universitas Gadjah Mada dan Departemen Kehutanan.

Pusat Pengendalian Pembangunan Ekoregion (P3E) Papua - KLHK. 2015. Laporan Penyusunan Perencanaan Ekosistem Danau Sentani dan Rawa Biru.

Pemerintah Kota Jayapura, 2014. Rencana Tata Ruang Wilayah Kota Jayapura 2013-2033.

Peraturan Pemerintah Republik Indonesia. 2012. PP Nomor 37 Tahun 2012 Tentang Pengelolaan Daerah Aliran Sungai.

Robert J. Kodatie, Suharyanto, Srisankawati, Sutarto Edhisono. 2002. Pengelolaan Sumber Daya Air dalam Otonomi Daerah. Yogyakarta : Penerbit Andi. 
Robert. J. Kodatie, Roestam Syarif, 2010. Tata Ruang Air. Yogyakarta : Penerbit Andi.

Robinson Tarigan, 2010. Perencanaan Pembangunan Wilayah. Jakarta : Bumi Aksara.

Rudi. P. Tambunan. 2005., Keberlanjutan Ekologis : Ketersediaan Sumberdaya Air. Dalam Bunga Rampai Pembangunan Kota di Indonesia Abad 21. Jakarta : URDI dan Yayasan Sugjianto Soegijoko bekerjasama dengan Lembaga Penerbit FE Universitas Indonesia.

Rustiadi E, Saefulhakim S.dan Panuju, D.R. 2004. Perencanaan dan Pengembangan Wilayah. Bogor : Fakultas Pertanian - IPB.

Samekto, C., \& Winata, E. S. 2010. Potensi Sumber Daya Alam dan Lingkungan. Jakarta: Pusat Teknologi Lingkungan-BPPT.

Sari, D. 2007. Perancangan Sistem Informasi Geografis Berbasis Web Menggunakan Mapserver. Medan: USU Repostory.

Sari, I. K., Limantara, L. M., dan Priyantoro, D. 2010. Analisa Ketersediaan dan Kebutuhan Air pada DAS Sampean. Malang: Universitas Brawijaya.

Siti Nurbaya. 2010. Geosains Untuk Pengambilan Keputusan: Pengalaman Legislasi. Dalam Reinvensi Pembangunan Ekonomi Daerah. Bagaimana Membangun Kesejahteraan Daerah. Jakarta : Penerbit Esensi.

Soemarto, C. 1987. Hidrologi Teknik. Surabaya: Usaha Nasional 